\title{
Issues In European Educational Change Over THE LAST 30 YeARS
}

\author{
Trevor E. Corner ${ }^{\mathrm{a}}$ \\ Middlesex University, UK
}

\begin{abstract}
Pan-European integration, based on theories of neo-functionalism and intergovernmentalism dates back to the Treaty of Paris of 1951, and has been an important force in the development of education and social policy across Europe since that time. This paper concentrates on the social, political and educational changes that have come about in many of the 28 sovereign states that now claim membership and are therefore subject to the EU treaties that cover educational policy and training issues. Choosing a selection of education developments, social policy and historical changes within European member states, the author seeks to illustrate how and where change has occurred and the implications that follow. It argues that, whilst European integration has been an important force of social and educational change, there are counteracting forces of national and regional interests, linguistic and cultural factors and historical trends that severely limit inter-governmental action and intention.
\end{abstract}

KEY WORDS: Europe, integration, policy, trans-nationalism, diversity .

\section{Introduction}

The first part of this paper offers an analysis of the national developments of education in western European countries which became members of the European Union (EU) prior to the the Nice Agreement in 2003; the second section will cover the member states of the EU which joined after 2003 and is predominantly about those countries from the central and eastern parts of the subcontinent, many of whom have been previously been under the educational and political influence of the Soviet Union and are moving through a transitional phase towards more western models. The relatively small, yet complex, educational systems of the Mediterranean countries, Cyprus and Malta, are also featured.

This review aims to provide a concise analytical overview of some major educational traditions and their recent evolution across Europe. At the same time it offers insights into the mosaic of schools and colleges, languages and social characteristics that each country exhibits through the education it provides for its citizens. Much of this review is based on the two books Education in the European Union (Corner, 2014/5) which contain chapters contributed by educational researchers from the current 28 countries of the EU with insights and experiential knowledge of the educational forces that have formed the European population as a whole in the current time. Together they shed some light on the countervailing forces for integration towards a European identity and the enduring wish to retain regional national and autonomy and locally-based school administrations.

\section{Seeking Identity and Unity in Europe}

Europe is the smallest continent; it is not even a continent but an appendage of Asia. It is smaller than Brazil and about half the size of China and the United States. It has, however, a high intensity of internal differences and contrasts across the approximately 46 countries of which it is composed. There are many small territories and islands that also claim some degree of social, political and thus educational separateness, whilst what draws the eastern 'border' of Europe would be a long term subject of debate. All of these countries have their unique yet overlapping histories, politics,

a Correspondence can be directed to: trevor.corner@btinternet.com 
languages and cultures - and educational systems. Their histories have been intensively analyzed and studied, though perhaps the role of education in the formation of the countries of Europe, and its contribution to the consciousness of what Europe was has been given less attention.

If the current view of Europe's destiny is one of gentle pessimism, it is at least a little more optimistic than in the late 1940s. The constituent states of Europe could no longer aspire, after 1945, to international or imperial status of pre- World War II times. The continent had not been able to liberate itself from Fascism by its own efforts nor, unassisted, to keep Communism at bay (and still may not be able to do today). Later decades of the twentieth century saw increasing disbelief in the great nineteenth-century theories of history with their assumptions of progress and change, revolution and transformation. The current theory that supports the idea of a "European model" results in a mixture of Social and Christian Democratic legislation which regulates social intercourse and inter-state relations. Embracing everything from child-care to inter-state legal norms, this European approach has stood for more than just the bureaucratic practices of the European Union and its member states; by the beginning of the $21^{\text {st }}$ century it had become a beacon and example for aspirant EU members and a global challenge to the United States.

The presence of Americans in Europe is an inheritance from the major wars and continues to the present day; anyone travelling across Europe over this period of time could, and still can, see the presence of the multitude of American military bases scattered across western Europe, their attendance on university and college campuses and through the lifestyle exemplified through social, digital and visual media. Conversely, it is also the case that Europeans travelling in the USA can reasses their self-image as Europeans, and perhaps only fully realise their European identity when immersed in an 'American' culture.

The concept of 'European identity' varies considerably and can refer to overcoming the German past, French republicanism and enlightenment, British nationalism and exceptionalism or the many other characteristics that come under the general theme of national identities. Although the EU has not succeeded in luring individuals away from these national identities, it has been assumed that European identification can only come about by becoming European through acquiring EU membership. Schilde (2014, p.652) quotes Jacques Delors when speaking in the USA in 1999:

We are doubtless rather too blase today to believe in the European dream as we did in the aftermath of the war. Nevertheless, Europe needs its dreams and without it, renaissance an reunification would be illusory.

Besides the many variables that contribute to any individual's sense of identity (national or European), expectation of personal or country benefits, ethnic, linguistic and minority status, it is education that is seen to play a vital role in developing the cognitive skills that can be assessed and the level of educational attainment that contributes to 'cognitive mobilisation' or the overall human capital in society.

This first section gives some insight into the commonalities and differences that educational developments have shown be it through local, regional, national or EU legislative means and to varying degrees takes in the perspective of those 70 years that have elapsed since the catastrophic collapse of Europe, east and west. A further analysis of those eastern European states that saw the phenomenon of European identity as positively identified in the Euro-15 as an aspiration for the fourteen countries that have joined the EU since 2013 (Corner, 2014). A similar analysis of educational change since 1989 for these eastern European countries is to be found in a sister volume to this (Corner, 2015).

Themes that are reviewed here include the regional and national contemporary educational structures and policies, research innovation and national trends in the light of their historical precedence, plus selected issues and problems such as historical and political trends and their effect of educational reform, systemic changes within the school and university systems, minority languages, regional change, and inter-cultural changes for indigenous and new immigrant populations. 


\section{Recent Evolution of National Education Systems in Western European Countries}

One of the most persistent attempts to measure the efficiency of national education systems over the years has been the Programme for International Student Assessment (PISA) studies which has now had 6 major surveys up to 2014. One aspect of its work has been to relate efficiency indicators academic results variables with resource variables used in the production of educational services via schools and other social institutions. Some general conclusions from this work are that European countries are characterised by weak management, whilst American schools (mainly Latin American) by a weak endowment of resources, and the Asians by a high level of heterogeneity. Thieme et. al. (2012) argue that standardised tests such as PISA are a good indicator of educational achievement, but do not capture so easily the aspects quality of performance of educational system managers. That is, whilst PISA results give a reasonable picture of academic achievement at a particular time, they do not indicate:

a. how these results were achieved through educational provision before the age of 15 years when the tests are administered - in the primary schools, for example.

b. the link with achievement with upper secondary and higher educational achievement (as PISA surveys progress however,this is becoming more possible).

c. the environmental factors surrounding the school systems that can and do affect achievement but cannot be easily measured or changed.

d. the numbers of students tested was about 400,000 across the 57 countries which have approximately 20 million of 15 year-old students in total; the sampling ratio is thus about 1 in 50.

The table below ranks the pre-2003 EU countries (with the exception of France and the inclusion of the UK), along with the highest and lowest performers of the 54 countries surveyed across the world by the Organisation for Economic and Co-operation Development (OECD).

Table 1. Resource, result and environmental variables based on PISA data (2006)

\begin{tabular}{|l|c|c|c|c|c|}
\hline & \multicolumn{2}{|c|}{ Desirable outputs } & \multicolumn{2}{c|}{ Inputs } & Environmental \\
\hline & $(1)$ & $(2)$ & $(3)$ & $(5)$ \\
\hline Finland & 546.9 & 555.8 & 0.513 & 0.641 & 0.256 \\
\hline Netherlands & 506.7 & 527.8 & 0.310 & -0.149 & 0.252 \\
\hline Ireland & 517.3 & 504.9 & 0.035 & 0.299 & -0.015 \\
\hline Belgium & 500.9 & 515.4 & 0.022 & 0.799 & 0.173 \\
\hline Germany & 494.9 & 509.7 & 0.448 & -0.762 & 0.293 \\
\hline Austria & 490.2 & 508.2 & 0.828 & 1.015 & 0.197 \\
\hline Sweden & 507.3 & 502.8 & 0.593 & 0.574 & 0.237 \\
\hline United Kingdom & 495.1 & 505.1 & 2.089 & -0.677 & 0.191 \\
\hline Denmark & 494.5 & 504.5 & 1.215 & -0.040 & 0.309 \\
\hline Luxemburg & 479.4 & 488.2 & 0.988 & -0.043 & 0.088 \\
\hline Spain & 460.8 & 484.2 & 0.234 & 0.954 & -0.311 \\
\hline Portugal & 472.3 & 468.5 & -0.662 & 2.256 & -0.617 \\
\hline Italy & 468.5 & 468.5 & 0.275 & 1.170 & -0.070 \\
\hline Greece & 459.7 & 466.3 & -0.296 & 1.769 & -0.153 \\
\hline Korea & 556.0 & 534.8 & 1.295 & -0.211 & -0.007 \\
\hline Kyrgystan & 284.7 & 316.3 & -2.556 & -1.737 & -0.659 \\
\hline
\end{tabular}

1- Reading achievement

2- Average achievement in Maths and Sciences

3/4- Educational and Human Resources

5- Surrounding Environmental Factors

Source: https://pisa2006.acer.edu.au/ 
The overall conclusions from this analysis have been that Finland (along with South Korea) had optimal systems with high achievement and strong input of material and human resources. Most of the other western European countries suffered managerial problems to a large extent, whilst Portugal and Greece (along with many of the eastern European countries) required a greater input of resources as well. The lowest country by achievement (Kyrgystan) was judged to be able to make the greatest improvement by substantially increasing human, and thus teaching, resources. Korea and the east Asian countries have consistently demonstrated high achievement scores.

The genesis of the PISA surveys and the approach of OECD to the collection of information and data went through a number of stages, initially favouring individual country studies, and guided by the 'Education at a Glance' studies that OECD continues to issue. Trohler (2013) has argued that it was the intervention of political and education influences from the USA which favoured the collection of information based on comparable data and measurable dimensions of inputs and outputs such as financial resources and educational achievement - indicators providing empirical and objective data.

If custom and law define what is educationally allowable within a nation, the educational systems beyond one's national boundaries suggest what is educationally possible and the study of comparative education exists to examine these possibilities. Thus much has been made of the global reach of the PISA (the Trends in International Mathematics and Science Study (TIMSS)) testing programmes and the potential for comparisons in achievement in different systems around the world. It is equally possible, particularly for large educational systems such as the USA or Russia to do cross-regional comparisons which give indicators of variable success within a political doctrine. The situation for Europe is somewhere between the two - national systems which guard their educational provision with some care, and an organisation such as the EU which seeks to augment its reach through social policy and educational programmes.

This point can be illustrated with a comparison of the TIMSS and PISA results for Finland and the Flanders of Belgium which represent the two most successful systems from the perspective of their mathematics achievement of their students. Both are economically strong, have similar populations and have been subjected considerable foreign influences in their development. Nonetheless, a closer examination of the scores achieved over a period of 20 years show considerable variability, though almost always outcomes above the media scores.

The Finnish success is well-known and has led to a plethora of books and articles examining possible reasons (Neimi et.al., 2012). In acknowledging the perceived success of Finnish education that date back the position of education within Finnish society and the prior organization of school and teacher education from the 1970s, Rautiainen and Kostiainen (2014) point out that the challenges for the future throughout the educational system are huge and emanate from the rapidly changing society, disputes over the aims of education and the impact of Information, Communications and Technology (ICT) to the need for continuing critical evaluation of the system and the essential requirement of maintaining a vision within the educational process.

In Belgium, the French, German and Dutch speaking communities are autonomous in their educational policies, though required to follow overarching federal state structures. In a discussion of the situation for Flanders in the regionalised systems, Standeart (2014) argues that further inclusiveness is required to cater for all needs of young people in Flanders, and there is greater uncertainty and less reliability developing in the assessment of achievement in the schools. The role of PISA studies continues to influence the international ratings of educational systems generally and to fuel the debate on how effective and instructive the national ratings of achievement are in judging the relative qualities of educational systems of EU neighbours.

The structure and basic laws of the Greek education system are influenced by EU policy which inspires national developments on the education and training processes. Economic austerity, which is manifested in increased rates of youth unemployment and high levels of skills shortages and mismatch with the labour market, have generated new policy considerations and challenges for the Greek education system. In Ireland too, where the downturn of the economy in the mid- 
2000s caused reforms to be eroded and even reversed. There are concerns around the teaching of mathematics, science and literacy which are under-performing from an international perspective plus the philosophical debates which underpin the educational system, including the place of religion in a pluralistic society.

Educational provision in Luxembourg shows that simple relationships between educational costs and performance are hard to find. A contemporary look at Luxembourg's educational system commonly addresses three issues which are used as corner-stones for discussing current changes and potential developments within this core European country: firstly, the internationally acclaimed trilingual education system; secondly, the poor outcomes of Luxembourg's schooling population in international standardized testing schemes; thirdly, the cost of Luxembourg's public education which ranks as the highest in Europe.

\section{Vocational and Higher Education}

Europe's influence on the vocational and higher systems from the 1970's to today's impact of the Bologna and Copenhagen Processes has especially been projected as a force for integration. Germany has traditionally provided a large proportion of its workforce with qualifications obtained in the dual vocational training system, a sector which has been institutionally divided from general academic schooling and higher education. However, due to the growing demand for abstract and codified knowledge but also given recent European reforms demanding greater educational mobility and lifelong learning, it has been a goal of the German policy makers to increase permeability between the different sectors of the educational system. The implementation of European educational guidelines has been significantly influenced by the specific mode of coordination in the German educational system and the national model of capitalism more generally.

\section{Recent Educational Change in Southern and Eastern European Countries}

For much of this second section the focus will be on those countries which joined the EU after 2003. These are predominantly those countries in the central and eastern parts of the subcontinent - Bulgaria, Croatia, Czech Republic, Estonia, Hungary, Latvia, Lithuania, Poland, Romania, Slovakia and Slovenia. Many of these countries had previously been under the educational and political influence of the Soviet Union and are now moving, hesitantly in some cases, through a series of transitional phases towards more western models. The relatively small, yet complex, educational systems of the Mediterranean islands, Cyprus and Malta, also formally joined the EU in 2004 and illustrate some of the potential educational opportunities and problems that arise when joining the European integration process. The many small islands scattered across the Mediterranean sea have long served as transitional links for populations of Eurasia and north African countries with a commitment to respond to the needs of the educational needs of migrants and refugees.

Taking the long view from the early $20^{\text {th }}$ century, Ringer has made the point that the role of social and political conflict cannot be ignored in the history of educational development (Ringer, 1979). The demand for increased opportunities, for 'democratization', has been an important factor in the enlargement of European education systems since 1918 and in the growth of enrolments progressively through systems more generally. A reform consensus emerged during the inter-war years, the importance of which stemmed from the wide support it had from the centre and left of the political spectrum. Segmentation in education was generally disapproved of as tending to preserve privilege, whilst greater inclusiveness was seen as an aid to the economy and as a democratic measure. If the breakdown of class barriers, increase of educational opportunities for lower-class students, and merit rather than family background determined access to education, then inclusiveness and progressiveness ensued.

During the period of the Cold War, a social and economic revolution transformed the Balkans. The all-important shift to an urban, industrial - and now post-industrialised - society brought 
fundamental changes to the nature of daily life and new challenges to domestic political elites. The ending of the Cold War has allowed the Eastern European states to participate in a different Europe, whose values are inscribed in its dominant cross-national institutions - the EU, the North Atlantic Treaty Organisation (NATO) and the Council of Europe. It has also transformed them geo-politically since they now find themselves at the centre of a greatly expanded market which takes in the Black Sea, the former Soviet Union and Central Asia, offering possibilities for business across a vaster area than at any time since the Ottoman Empire. As well therefore as inheriting the educational patterns of the past they have to take on dilemmas familiar to most of the European countries: how to reconcile older patterns of educational provision, absorb the competitive pressures of global capitalism and mould the output of educational systems to build prosperous economies and allow social democracy to flourish (Mazower, 2000).

\section{Education and Life Chances}

The eastern European countries tend to illustrate an inheritance of Soviet models and philosophies of education and the countervailing forces for integration towards a European identity, as well as an enduring wish for regional autonomy and locally-based school administrations. The role of education as a determinant of individual life chances and as a predictor of young peoples' chances in the labour market and society are subjects of continual discussion for teachers and educationalists. It is a central part of the professional educationalists' existence to make the case for the importance of education 'from cradle to grave' and act as both a protagonist and critic.

The power of a national state, and the extent to which each interacts with others, are expressions of the historic, political and economic strands which infuse and inform an education system. The western European social democratic view has been to argue that, by relieving the individual of the hazards of poverty, by providing more opportunity, not least by means of education, for self-development and by limiting the arbitrary use of power by the holders of money and status, the margin of individual options has been widened. The liberal consensus is that perhaps the over-riding purpose of the educational system should be to help the individual to realise his and her potentialities, abilities, and interests as they develop from interaction amongst the agents of educational influences (Husen, 1979).

Writing in 1979, Grant interpreted the purpose of education in the U.S.S.R. as primarily a political tool for the construction of a communist society and quotes the Basic Law on Education (1974): 'The goal of public education in the U.S.S.R. is the preparation of a highly educated, wellrounded, physically healthy and active builders of communist society' (Grant 1979, p.25). Was it the case that in gaining membership of the European Community in 2003/4, the governments of Bulgaria, Croatia, Czech Republic, Estonia, Hungary, Latvia, Lithuania, Poland, Romania, Slovakia and Slovenia (and, coming from a different perspective, Cyprus and Malta) were taking on acceptance of western European values of social solidarity which finds political and legal expression in the welfare state and a programmatic commitment to free education from kindergarten through to university irrespective of political ideology? The question perhaps, especially at the present time, is whether this rhetoric of social solidarity can be translated into constitutional guarantees which can allow the European Constitution to gain traction of identity and identification for the peoples of the eastern European countries (Weiler, 2003).

The major trends being examined here are therefore the evolution of the school systems, the main factors that have shaped these systems in the past 30 years, the political changes during the late 1980 's and the expansion of the European Union in May 2004 when it formally accepted a further 10 member states (eight of the then central and eastern Europe (CEE) countries with Bulgaria and Romania joining in January 2007. The view of the European Commission in Brussels was that this rapid enlargement enhanced the prospects of embracing the cultural heritage of a 'greater Europe'; at the same time, of course there was also an increase in cultural heterogeneity, social disparities and economic imbalances and their ensuing influences. 


\section{Diversity, States and Regions}

Whilst on his trans-Europe walks following the Maritza river near Plovdiv in Bulgaria, Patrick Leigh Fermor relates some of the colours and complexities of cultures to be found in that region during the 1930s:

There was a pinnacle mosque and suddenly Turks - sashed in red like the Bulgars, but they wore baggy black trousers and slippers and scarlet fezzes. I might also have seen some Kutzovlachs, or semi-nomadic Aruman shepherds speaking a low Latin Dialect laced with Slav and akin to Rumanian. The Pomaks are said to be Bulgarians converted to Islam after the Turkish conquest. On either side of the border live tiny pockets of Kizilbashi, red-headed and Shi'ite Muslims. A turn in the lane and all the shops would become Greek and the air would ring with this language (Fermor 2013, pp.28-29).

Today, cultural and linguistic diversity persists in many of the CEE countries (and may well increase in the light of the current migrations from Eurasia and northern Africa) but the major changes in educational provision have grown step-by-step with radical political and economic transformations; new patterns of education, new types of schools and new institutional structures have emerged. Whilst some changes have reached back to a pre-communist era, others have adopted Western European trends. For example, the structure of post-secondary education has been diversified, both through the introduction of secondary vocational programmes and the appearance of private institutions. Hungary, the Czech Republic, Slovenia, Slovakia and Poland, having been part of the Austro-Hungarian Empire, inherited influences from the Austrian and German education and training systems, whilst Hungary, the Czech Republic and Slovakia also introduced early selection in prestigiously academic gymnasia, along with a dual system of vocational training (Graf, 2015). The three Baltic states of Estonia, Latvia and Lithuania have been influenced by both German and Russian education traditions and have significant Russian minority populations. Continuing links with the Scandinavian countries from the 1990s have encouraged secondary-based vocational education and enhanced social welfare initiatives. Significant increases in the tertiary and private sectors are also common to these countries. As in the case of Finland, there have been attempts to explain the relatively high educational performance of a number of these smaller states, especially Estonia. The rapid application of new information technologies during the mid-1990s through free public internet access, paperless government, internet voting and introduction of computer laboratories, upgraded equipment and internet access in most schools enabled a leap-frog development in educational achievement. At the same time, the practice of using a teacher dedicated to the management and coordination of all of any one class's teachers has enabled the close monitoring of each child's progress in considerable detail (Stevick, 2015).

By the end of the Ceaucescu period less than $8 \%$ of secondary students were enrolled in theoretical (academic) education so that Romania too has had a relatively late education expansion with continuing Soviet influences remaining into the early years of the present century (Mocanu et. al., 2008). Bulgaria inherited a centralised economy and standardised education system from the Soviet era and found difficulties in the transition to a market-based economy, especially during the 1960s. Whilst open to European integration it had some reservation in fully exposing changes in general educational attainment to international gaze as illustrated by its tentative adoption of international achievement tests such as TIMSS and has lagged some other eastern countries with vocational education at lower-secondary level remaining low and ethnic groups achieving significantly lower educational levels (Kogan et.al., 2008). The Bulgarian system has nonetheless continued to react to democratic changes and the main educational law of 1991 established a new educational structure whilst the curriculum law of 1999 established general basic standards and grades in line with the social and cultural changes that have taken place of the past two decades (Bankov, 2015). 


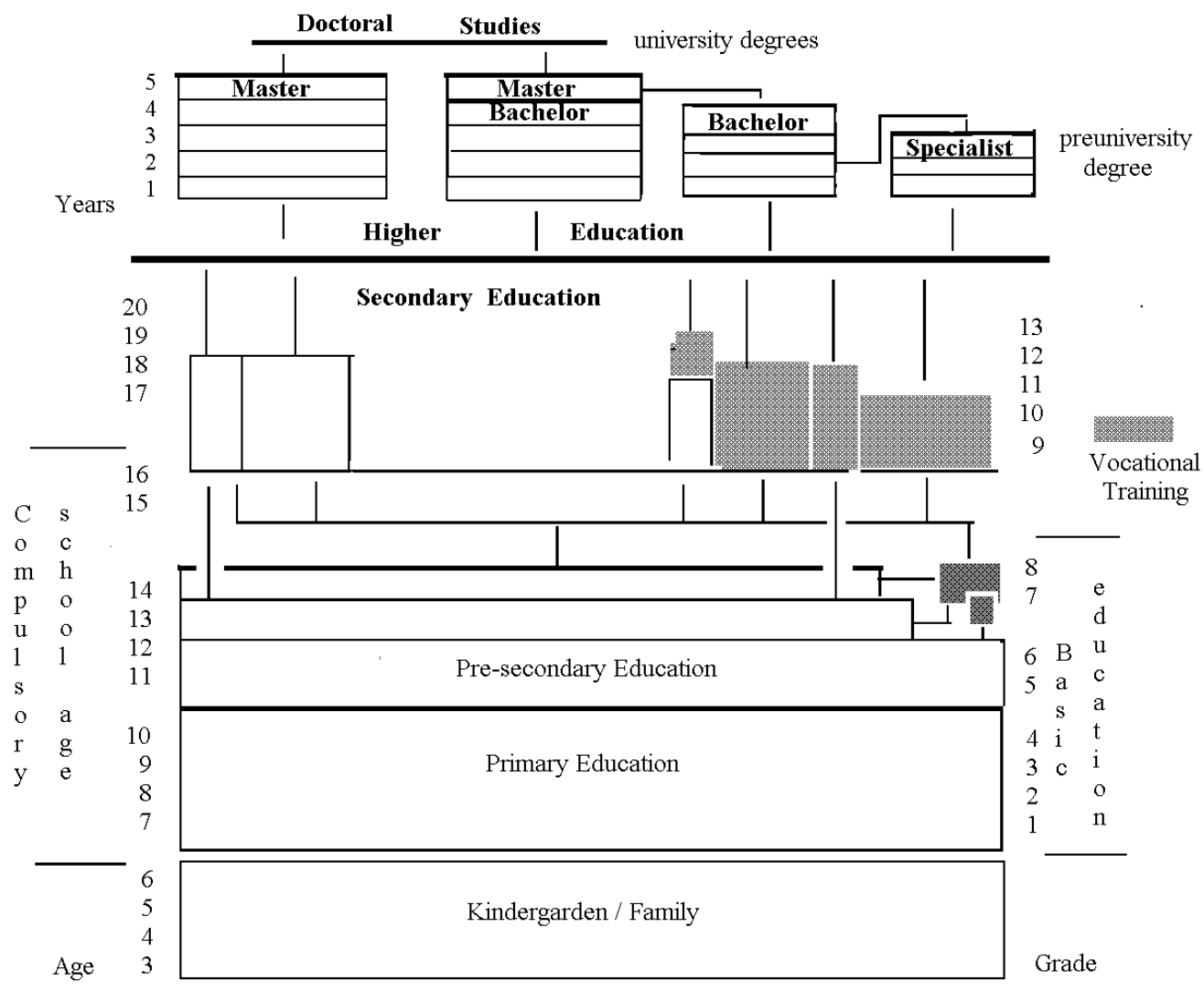

Figure 1: Structure of the educational system of Bulgaria (Ministry of Education, 2006)

Malta and Cyprus both officially joined the European Union in May 2004 as a part of a new enlargement. The smallest member of the community by size and population, Malta continues to debate the benefits and drawbacks of membership though educationalists see some benefits in the access to education in other European states, whilst others conclude that Malta is becoming a staging post for refugees seeking access to the European continent which membership has inadvertently encouraged. Borg and Mayo (2015) have particularly examined the role that international influences have had on education, how achievement is seen as both a passport and cogent element of life, and the growth of adult and higher education have been emphasised as fundamental elements for a competent workforce.

The accession or the Republic of Cyprus was again part of the 2004 enlargement, and had been anticipated as a potential force for the unification of the island (much in the same way as the potential for the alleviation of Belgian regionalism would be hopefully realised via the 1957 Treaty of Rome). In practice the negotiations between the Cypriot communities have been complicated by this accession and whilst, legally at least, EU regulations cover the whole of the island, they are enforceable only in the southern part. Whilst recent educational developments on the island are shaped by local, post-colonial anxieties, ideologies and histories as well as by Greek national culture and identity, the recent internationalisation of Cyprus with regards to membership of the EU, UNESCO and OECD have become the dominant factors in the last 20 years (Klerides and Philippou, 2015). 


\section{Enlargement and Integration or Dissipation and Confrontation?}

Writing in 2007, Symecki has pointed to political economic and educational factors that drove the eastern and southern European countries to anticipate EU membership with enthusiasm.

This enlargement must not be the last. It is difficult to define the limits to 'Europe'. And perhaps it is useless to discuss where Europe ends, while the new Member States are likely to become diligent and disciplined neophytes. If the old EU-15 becomes more active in fostering integration, the diligent converts will follow suit, If the path to be chosen by the EU is bold and far-reaching, then the marriage (of enlargement) could be perhaps be stormy and adventurous, but not boring (Symecki 2007, p. 410).

The current view is that there is a great deal of equivocation on the direction of educational change, and the role and functions of European integration for the countries concerned. To a certain extent enthusiasm for integration has waned and the sought-for economic drivers for monetary union remain elusive. Whilst the Lisbon-Copenhagen-Maastricht and Bologna processes have pushed educational integration a step further, particularly in Vocational Education and Higher Education, the sought after marriage of the EU15 to the EU13 is turning out to be stormy and adventurous, but the overall direction of travel is not easy to discern.

There are currently just over 500 million people in the EU countries; which compares with 325 million for the USA, frequently cited as a similar world region and friendly competitor. There will soon be over one billion teenagers on the planet and, as James Martin has pointed out, this 'Transition Generation' is likely to benefit from much 'free' education via internet forums, as well as within formal schooling; this is an area of educational change where the EU countries have yet to make an impact. On the grand scale much of future educational development could come from the deliberate transfer of knowledge of how to cure diseases, grow food and create employment; this process of educational transfer between the major regions of the world would enable populations to grow at a slower rate and reduce poverty (Martin, 2006).

\section{References}

Bankov, K. (2015). Bulgaria: An Overview. In T. Corner (Ed.) Education in the European Union: Post2003 Member States, London: Bloomsbury Academic, pp.9-26.

Borg, C. and Mayo, P. (2015). Malta: An Overview of European Influences on Educational Reforms. In T. Corner (Ed.) Education in the European Union: Post-2003 States. London: Bloomsbury Academic, pp.152-171.

Corner, T. (Ed.) (2014). Education in the EU: Pre-2003 member states. London: Bloomsbury Academic. Corner, T. (Ed.) (2015). Education in the EU: Post-2003 member states. London: Bloomsbury Academic. Delors, J. (1999). Reuniting Europe: Our Historic Mission. Aspen Institute: Wallenberg Lecture, November.

Fermor, P.L. (2013). The Broken Road: from the Iron Gates to Mount Athos. London: John Murray. Grant, N. (1979). Soviet Education. Harmondsworth: Pelican Books.

Graf, L. (2015). Germany: Stability and Change . In T. Corner (Ed.) Education in the European Union: Pre-2003 Member States. London: Bloomsbury Academic, pp. 125-154.

Griffin, R. (2014). Ireland: Structure and Reform. In T. Corner (Ed.) Education in the European Union: Pre-2003 Member States. London: Bloomsbury Academic, pp. 179-200.

Hofman, R., Hofman, W., Gray J. and Daly P. (2004). Institutional Context of Education Systems in Europe: A Cross-Country Comparison on Quality and Equity. London: Kluwer Academic.

Horne, K. and Weber, J. (2014). Luxembourg: Language and Education. In T. Corner (Ed.) Education in the European Community: Pre-2003 Member States. London: Bloomsbury Academic, pp. 227-244. 
Husen, T. (1979). The School in Question: A Comparative Study of the School and its Future in Western Societies. Oxford: Oxford University Press.

Judt, T. (2010). Postwar: A History of Europe since 1945. London: Vintage Books.

Klerides, E. and Philippou, S. (2015). Cyprus: Exploring Educational Reform 2004-2014. In T. Corner (Ed.) Education in the European Union: Post-2003 Member States. London: Bloomsbury Academic, pp. 51-74.

Kogan, I., Gebel, M. and Noelke, C. (2008) (Eds). Europe Enlarged: A Handbook of Education, Labour and Welfare Regimes in Central and Eastern Europe. Bristol: The Policy Press.

Martin, J. (2006). The Meaning of the $21^{\text {st }}$ Century: A Vital Blueprint for Ensuring our Future. London: Random House.

Mazower, M. (2000). The Balkans: From the End of Byzantium to the Present Day. London: Orion.

Meyer, H-D. and Benavor, A. (2013). PISA, Power and Policy: the Emergence of Global Educational Governance. Oxford: Symposium Books.

Ministry of Education (2006). National Programme for the Development of the School: Education and Training 2006-2015. Sofia: Ministry of Education.

Mocanu, C. (2008). Romania. In I. Kogan, M. Gebel and C. Noelke (Eds.) Europe Enlarged: A Handbook of Education, Labour and Welfare Regimes in Central and Eastern Europe. Bristol: Policy Press, pp. 295-304.

Niemi, H., Toom, A. and Kallioniemi, A. (Eds.) (2012). Miracle of Education: The Principles and Practices of Teaching and Learning in Finnish Schools. Rotterdam: Sense Publications.

Psifidou, I. and Pouliakis, K. (2015). Greece: Vocational Education and Training in Economic Change. In T. Corner (Ed.) Education in the European Union: Pre-2003 Member States. London: Bloomsbury Academic, pp. 155-178.

Rautiainen, R. and Kostiainen, E., (2014). Finland: Policy and Vision. In T. Corner (Ed.) Education in the European Union: Pre-2003 Member States. London: Bloomsbury Academic, pp. 91-108.

Ringer, F.K. (1979). Education and Society in Modern Europe. London: Indiana University Press.

Schilde, K. E. (2014). Who are the Europeans? European Identity Outside of European Integration. Journal of Common Market Studies, 52(3), pp. 650-667.

Standeart, R. (2014). Belgium: Regional Development. In T. Corner (Ed.) Education in the European Union: Pre-2003 Member States. London: Bloomsbury Academic, pp. 41-62.

Stevick, D. (2015) Estonia: An Overview (1970-2014). In T. Corner (Ed.) Education in the European Union: Post-2003 Member States. London: Bloomsbury Academic, pp. 93-111.

Symecki, P. (2007). Some Remarks on Poland's Membership of the EU: The Qualities in Demand. In J. Weiler, I. Begg and J. Petersen, J (Eds.) Integration in an Expanding European Union: Reassessing the Fundamentals. Oxford: Blackwell, p. 410.

Thieme, C., Gimenez, V., and Prior, D. (2012). A comparative analysis of the efficiency of national education systems. Asia Pacific Education Review,13(13), pp. 1-15.

Trohler, D. (2013). The OECD and Cold War Culture: thinking historically about PISA. In H.D Meyer and A. Benavot (Eds.) PISA. Power and Policy: the Emergence of Global Educational Governance. Oxford: Symposium Books, pp. 141-161.

Weiler, J. (2003). A Constitution for Europe? Some Hard Choices. In J. Weiler, I. Begg and J. Petersen (Eds). Integration in an Expanding European Union: Reassessing the Fundamentals. Oxford: Blackwell, pp. 17-33. 